\title{
Effect of Various Heat and Thermo-mechanical Treatments on Low Alloyed CMnAlNb High Strength Steel
}

\author{
Ludmila Kučerová (0000-0001-7154-7829), Iveta Tichá (0000-0002-7628-0665), Adam Stehlík \\ Regional Technological Institute, University of West Bohemia in Pilsen, Univerzitní 8, 30614 Plzeň, Czech \\ Republic.E-mail: skal@rti.zcu.cz, ichenati@rti.zcu.cz,stehlika@rti.zcu.cz.
}

Low carbon low alloyed high strength steel with the chemical composition suitably designed to support the stabilization of retained austenite was used in this work. The steel was processed by conventional annealing for a reference and several different heat and thermo-mechanical treatments were further proposed to test typical TRIP (transformation induced plasticity), DP (dual phase) steel and QP (quenching and partitioning) processing routes. All the processing methods used the same soaking temperature of $1050^{\circ} \mathrm{C}$. Processed samples were subjected to metallographic analysis, hardness measurement and tensile test to characterise resulting microstructures. While simple annealing reached tensile strength of 861 MPa with $25 \%$ of total elongation, the best combination of the highest tensile strength of $903 \mathrm{MPa}$ and a total elongation of $32 \%$ was obtained after processing typical for TRIP steel. QP treatment resulted in the highest tensile strength of $1289 \mathrm{MPa}$ with a total elongation of $19 \%$.

Keywords: TRIP steel, DP steel, QP treatment, high strength steel

\section{Introduction}

The development of high strength steels has gone through several stages in the last two decades. Among the first group of high strength steels are low alloyed DP (dual phase) and TRIP (transformation induced plasticity) steels [1-3]. For both of them, special heat or thermo-mechanical treatment methods were developed, respectively for steels with carbon contents typically around $0.2 \%$. Furthermore, both types of steel were also investigated mainly for applications in the automotive industry. While DP steels aim at a twophase microstructure consisting of the mixture of ferrite and martensite [2], the TRIP steels possess more complex microstructures of ferrite, bainite and retained austenite [3-4]. DP thus requires quick quenching once the sufficient amount of ferrite is obtained, while TRIP steels need a second isothermal hold at the temperature of intensive bainitic transformation to obtain a special, carbide-free bainite consisting of the bainitic ferrite and retained austenite laths [4]. Nevertheless, the TRIP steel requires alloying with manganese and silicon to retain a sufficient amount of retained austenite at room temperature. However, silicon was observed to decrease the surface quality of the steel and makes substantial troubles in subsequent hot-dip galvanizing, so it was later fully or partially substituted by aluminium. Furthermore, other alloying or microalloying elements such as $\mathrm{Cu}, \mathrm{Cr}, \mathrm{Nb}$ or $\mathrm{Mo}$ have been also often tested in DP and TRIP steels [5]. The positive effect of a controlled fraction of retained austenite at mechanical properties of TRIP steels was later successfully used also in the QP (quenching and partitioning) process which produced predominantly martensitic or martensitic-bainitic microstructures with thin films of retained austenite along lath boundaries [6 -9]. This process requires quite a tricky heat treatment with quenching interrupted between the temperatures of martensite start and martensite finish and subsequent heating up to the isothermal hold at partitioning temperature where carbon is allowed to diffuse from the super-saturated martensite into the remaining austenite [10]. All three processing methods were tested within this work on low carbon low alloyed $\mathrm{CMnAlNb}$ steel to optimise its mechanical properties.

\section{Experimental program}

High strength low alloyed steel $\mathrm{CMnAlNb}$ was used in this work (Tab. 1). This steel is alloyed with manganese to support austenite retention during heat or thermo-mechanical treatments. Moreover, silicon and aluminium have similar effects, they provide solid solution hardening of the ferrite at one hand and postpone cementite precipitation during the treatment on the other hand [11]. If carbon is not consumed by the precipitation of the carbides, it is available in a larger amount for chemical stabilization of the remaining austenite. As silicon has a stronger effect in solution strenghtening and precipitation hindering than aluminium, a complete substitution would decrease the strength of the steel and therefore only partial substitution of silicon with aluminium was chosen. Microalloying with niobium was proved to postpone the 
pearlite transformation in this type of low alloyed steel which is also advantageous for increasing carbon content, remained in the matrix, and for supporting the austenite stabilization [12-16].

The steel was vacuum cast and the $250 \mathrm{~kg}$ ingot Tab. 1 Chemical composition of CMnAlNb steel (weight \%)

\begin{tabular}{|l|l|l|l|l|l|l|l|l|}
\hline & $\mathrm{C}$ & $\mathrm{Si}$ & $\mathrm{Mn}$ & $\mathrm{P}$ & $\mathrm{S}$ & $\mathrm{Cr}$ & $\mathrm{Al}$ & $\mathrm{Nb}$ \\
\hline $\mathrm{CMnAlNb}$ & 0.2 & 0.6 & 1.5 & 0.008 & 0.003 & 0.19 & 1.5 & 0.06 \\
\hline
\end{tabular}

All the samples were processed using a thermomechanical simulator to ensure the precise utilization of prescribed treatment conditions. The actual temperature of the sample was checked by an attached thermocouple. All heat (HT) and thermo-mechanical (TMT) treatments were carried out with the same soaking temperature of $1050^{\circ} \mathrm{C}$. This temperature corresponds to that conventionally used for the controlled rolling of this type of low alloyed steels and it lies in a fully austenitic region. Annealed samples had a 20-min hold at this temperature, while all other samples had shorter soaking of only $100 \mathrm{~s}$. In all thermo-mechanical treatments, the same $10 \%$ compressive deformation steps were applied at the temperatures of $1050^{\circ} \mathrm{C}$ and $750^{\circ} \mathrm{C}$. The first deformation was always carried out at the end of the soaking hold while the second one was reached during the cooling (Fig. 1).

The reference treatments were simple-annealed at $1050{ }^{\circ} \mathrm{C}$ for twenty minutes followed by a slow cooling at $1{ }^{\circ} \mathrm{C} / \mathrm{s}$ to room temperature (1-annealed). Furthermore, two compressive deformation steps were incorporated into this thermal cycle (2-annealed TMT).

For DP steel processing, thermo-mechanical treatment with $100 \mathrm{~s}$ soaking hold at $1050^{\circ} \mathrm{C}$ was proposed (3-DP TMT). Two compressive deformation steps were carried out at $1050{ }^{\circ} \mathrm{C}$ and $720^{\circ} \mathrm{C}$. The steel was cooled by $14{ }^{\circ} \mathrm{C} / \mathrm{s}$ within this temperature interval to allow the ferrite formation. After the second deformation, the quicker cooling by $50{ }^{\circ} \mathrm{C} / \mathrm{s}$ to room temperature was used to enhance martensite formation.

In the next step, TRIP steel heat treatment was designed with 100 s hold at $1050^{\circ} \mathrm{C}$, followed by $14^{\circ} \mathrm{C} / \mathrm{s}$ cooling down to the isothermal hold at $425{ }^{\circ} \mathrm{C}(4-$ TRIP HT). The hold at this temperature was $600 \mathrm{~s}$ and it was planned in the bainitic transformation region based on the previous works on the optimization of heat treatment of CMnAlNb steel [13]. The TRIP processing was also carried out in the form of thermomechanical treatment with the same two deformation steps applied at the temperatures of $1050^{\circ} \mathrm{C}$ and 720 ${ }^{\circ} \mathrm{C}$ (5-TRIP TMT).

The last tested method was QP with very quick cooling by $50{ }^{\circ} \mathrm{C} / \mathrm{s}$ from the soaking temperature of $1050{ }^{\circ} \mathrm{C}$ to the quenching temperature of $300{ }^{\circ} \mathrm{C}(6-$ $\left.\mathrm{QP}-300{ }^{\circ} \mathrm{C}\right)$ or $350^{\circ} \mathrm{C}\left(7-\mathrm{QP}-350{ }^{\circ} \mathrm{C}\right)$. Once the que- was cut into four parts. Parts of the ingot were soaked at the temperature of $1150{ }^{\circ} \mathrm{C}$ and forged into bars. The bars were finally annealed for two hours at 950 ${ }^{\circ} \mathrm{C}$ and air-cooled to room temperature. nching temperature was reached (according to the attached thermocouple), the samples were heated by 50 ${ }^{\circ} \mathrm{C} / \mathrm{s}$ to the partitioning hold of $600 \mathrm{~s}$ at $425^{\circ} \mathrm{C}$.

The obtained microstructures were characterised by scanning electron microscopes Vega (Tescan) and EVO 25 (Zeiss) and by tensile tests. A retained austenite volume fraction was determined by an X-ray diffraction phase analysis.

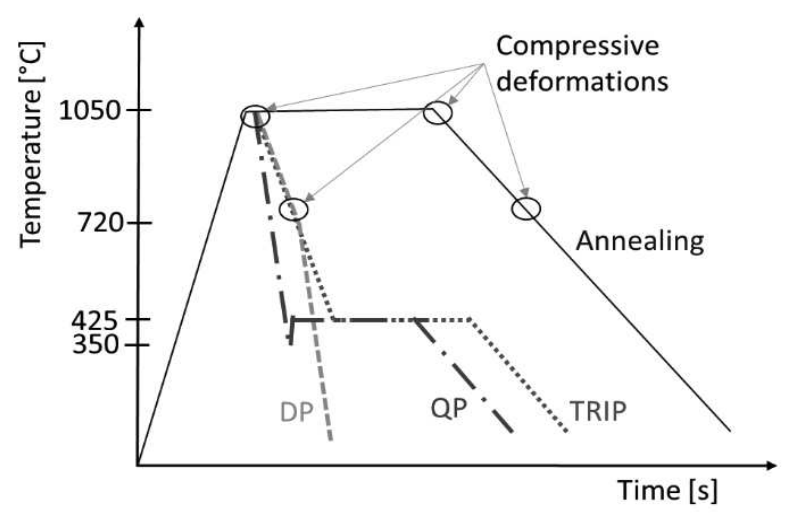

Fig. 1 Heat and thermo-mechanical treatment schedules of CMnAINb steel

\section{Results and discussion}

The microstructure of the annealed sample was bainitic-ferritic with a chain of fine grains of proeutectoid ferrite placed at prior austenite grain (PAG) boundaries and coarse bainitic blocks (Fig. 2a). The incorporation of two deformation steps into the annealing thermal cycle resulted in refinement of bainitic blocks and a slight increase in ferrite volume fraction. The microstructure was still bainitic-ferritic with ferrite growing mainly at PAG boundaries (Fig. 2b).

The samples consisted of around $10 \%$ of retained austenite, even though no special treatment was carried out to enhance austenite stabilization (Tab. 2). Due to very similar microstructures, both samples 1annealed and 2-annealed-TMT had very similar mechanical properties, reaching the tensile strength of $860 \mathrm{MPa}$ with the elongation of $25 \%$.

DP processing unfortunately did not result in an expected two-phase microstructure. On the other hand, the resulting microstructure consisted of a martensitic-bainitic mixture (Fig. 2c, d). This result indicates that the cooling rate from the soaking temperature 
was still too high to enable ferrite formation. Considering the small amount of ferrite in previous annealed samples with cooling at $1{ }^{\circ} \mathrm{C} / \mathrm{s}$, it further shows that the suitable cooling rate would have to be significantly lower than this. Thus, this would make the processing rather inconvenient, combining extremely slow and quick cooling rates in the same method. In the case of

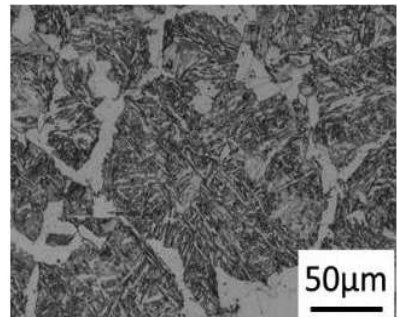

\section{a) 1- annealed}

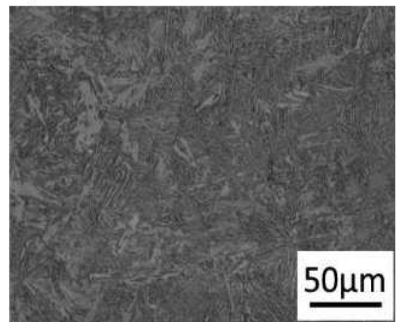

e) 4-TRIP-HT

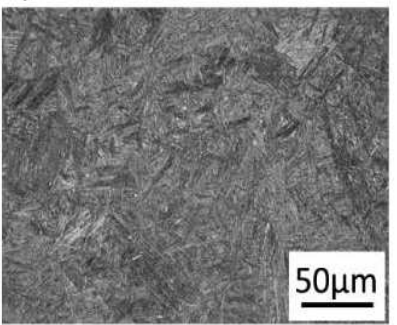

i) $6-Q P-300^{\circ} \mathrm{C}$

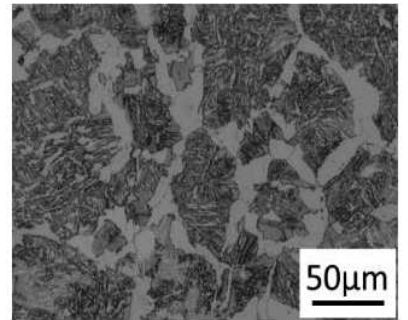

b) 2-annealed TMT

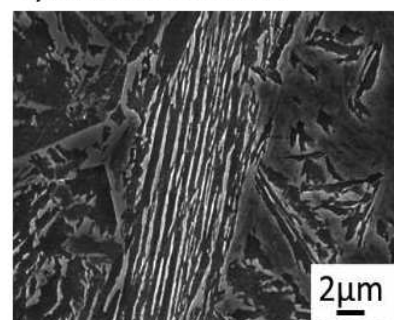

f) 4-TRIP-HT

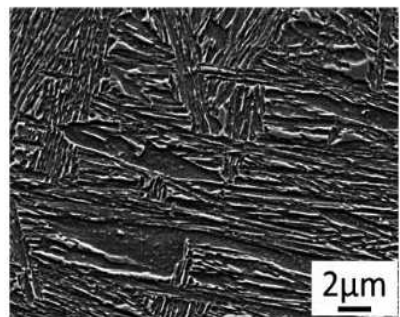

j) $6-Q P-300^{\circ} \mathrm{C}$ this DP processed steel, the more suitable way how to create the ferrite-martensite microstructure seems to be the intercritical annealing route which creates the substantial ferrite fraction directly during the soaking. Due to the quenched microstructure, the tensile strength of this sample reached nearly $1200 \mathrm{MPa}$ with a total elongation of $10 \%$.

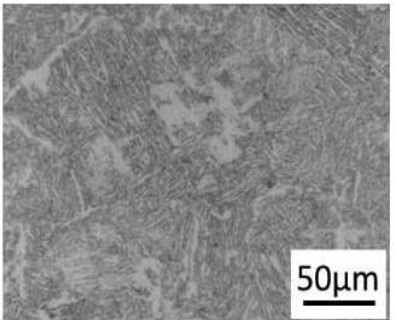

c) 3-DP-TMT

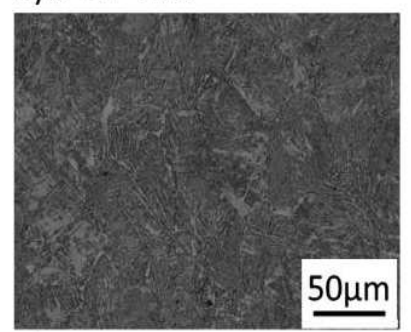

g) 5-TRIP-TMT

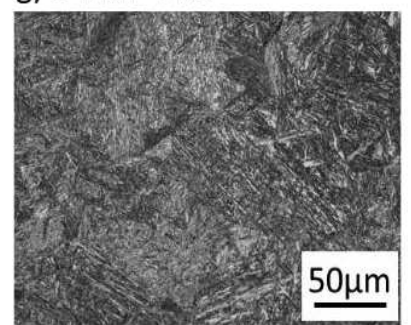

k) $7-Q P-350^{\circ} \mathrm{C}$

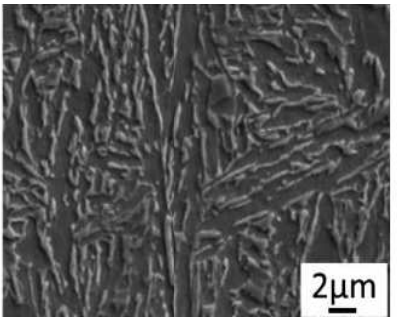

d) 3-DP-TMT

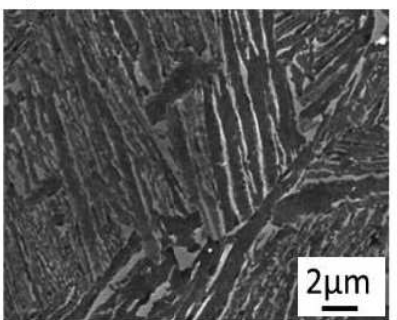

h) 5-TRIP-TMT

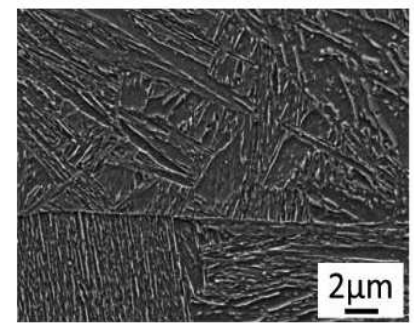

I) $7-Q P-350^{\circ} \mathrm{C}$

Fig. 2 Microstructure of the CMnAINb steel, light microscopy a)-c), e), g), i),k) and scanning electron microscopy d), f), b), j), l).

Tab. 2 Mechanical properties: yield tensile strength (YTS), ultimate tensile strength (UTS), total elongation (TE) and retained austenite volume fraction $(\mathrm{R} A)$

\begin{tabular}{|l|l|l|l|l|}
\hline & YTS [MPa] & UTS [MPa] & TE [\%] & RA [\%] \\
\hline 1-annealed & $520 \pm 8$ & $861 \pm 1$ & $25 \pm 1$ & 11 \\
\hline 2-annealed-TMT & $520 \pm 8$ & $861 \pm 1$ & $25 \pm 1$ & 9 \\
\hline 3-DP-TMT & 686 & 1193 & $10+3$ & Not detected \\
\hline 4-TRIP-HT & $735 \pm 5$ & $903 \pm 10$ & $32 \pm 0$ & 12 \\
\hline 5-TRIP-TMT & $808 \pm 1$ & $935 \pm 4$ & $28 \pm 1$ & 11 \\
\hline 6-QP-300 ${ }^{\circ} \mathrm{C}$ & $1056 \pm 3$ & $1215 \pm 2$ & $18 \pm 0$ & 9 \\
\hline 7-QP-350 ${ }^{\circ} \mathrm{C}$ & $1045 \pm 20$ & $1289 \pm 3$ & $19 \pm 0$ & 6 \\
\hline
\end{tabular}

TRIP steel processing without deformation (4TRIP-HT) resulted in a multiphase microstructure which mainly consists of the carbide-free bainite with small occasional ferritic areas (Fig. 2e, f). About 12\% of retained austenite was detected by an X-ray diffraction phase analysis. The bainite is mainly granular with occasional areas of relatively long bainitic laths. Granular bainite further contained a larger island of martensite or M-A (martensitic-austenitic) constituent. These islands of austenite remained in the microstructure during the isothermal hold at $425{ }^{\circ} \mathrm{C}$ which was not enough stable to resist martensitic transformation during the final cooling to room temperature. In the case of M-A constituent, areas of retained austenite remained in the mainly martensitic islands. This is a typical microstructure feature in low alloyed TRIP steels. Observed mechanical properties were also very promising for this type of steel, with the tensile strength of $900 \mathrm{MPa}$ and the elongation of $32 \%$ (Tab. 2). 
Very similar microstructure (Fig. 2g,h) with the same volume fraction of retained austenite and similar mechanical properties were also reached in the case of thermo-mechanical TRIP processing (5-TRIP-TMT). The deformation refined the lath bainite in the microstructure and increased its amount at the expense of granular bainite. This slightly increased the yield and tensile strength of the steel.

Finally, QP processing with two different quenching temperatures was investigated. The choice of quenching temperature determines the fraction of austenite and martensite prior to partitioning hold. During this hold, carbon can diffuse from martensite into austenite to stabilize it. Lower quenching temperature would result in the transformation of a larger amount of martensite. However, it should be noted that a higher austenite fraction after quenching does not necessarily ensure a higher retained austenite fraction after the final cooling, as more carbon will be needed to stabilize it. This can be seen nicely from the retained austenite fractions obtained in samples $6-\mathrm{QP}-300^{\circ} \mathrm{C}$ and $7-\mathrm{QP}-350^{\circ} \mathrm{C}$. Nevertheless, the microstructure of those samples showed otherwise little difference and both consisted of fresh and tempered martensite (Fig. 2i-l). The traces of precipitates were found in 7-QP$350^{\circ} \mathrm{C}$ suggesting that carbide precipitation was not quite successfully prevented during partitioning hold at $425{ }^{\circ} \mathrm{C}$. This might be contributed to a rather high partitioning temperature used in this treatment, which is more than $100^{\circ} \mathrm{C}$ above the temperatures typically used for QP steels [14]. However, those fine precipitates might contribute to the highest strength of this sample $\left(7-\mathrm{QP}-350^{\circ} \mathrm{C}\right)$ which reached nearly $1300 \mathrm{MPa}$ and was accompanied by a very promising elongation of $19 \%$.

\section{Conclusions}

Four methods of heat and thermo-mechanical treatments typically used for various high strength steels were tested on low-alloyed $\mathrm{CMnAlNb}$ steel, resulting in a wide range of mechanical properties. The annealing resulted in a bainitic-ferritic microstructure with a good combination of a tensile strength of $860 \mathrm{MPa}$ and an elongation of $15 \%$. TRIP steel processing produced a bainite-based microstructure with $12 \%$ of retained austenite, a tensile strength of $900 \mathrm{MPa}$ with $32 \%$ of total elongation. The highest tensile strength of $1300 \mathrm{MPa}$ with a total elongation of $19 \%$ reached the martensitic microstructure obtained after QP processing.

\section{Acknowledgement}

The present contribution has been prepared with the support of the student grant competition of University of West Bohemia in Pilsen, SGS 2019019.

\section{References}

[1] SOLEIMANI, M., KALHOR, A., MIRZADEH, H. (2020). Transformation-induced plasticity (TRIP) in advanced steels: A review. In: Materials Science and Engineering: $A$, Vol. 795, pp. 140023-37. Elsevier Ltd. United Kingdom.

[2] HU, X. et al. (2020). Linking constituent phase properties to ductility and edge stretchability of two DP 980 steels. In: Materials Science and Engineering: A, Vol. 780, pp. 139176-86. Elsevier Ltd. United Kingdom.

[3] KUČEROVÁ, L., (2017). [17]The effect of two-step heat treatment parameters on microstructure and mechanical properties of 42SiMn stee. In: Metals, Vol. 7, No. 12, pp. 537. MDPI, Switzerland

[4] KUČEROVÁ, L., JANDOVÁ, A., RUBEŠOVÁ, K. (2019). Microstructure Analysis and Mechanical Properties of Low Alloyed Steel with Retained Austenite Obtained by Heat Treatment. Manufacturing Technology, 2019, Vol. 19, No. 2, pp. 243-247. ISSN: 1213-2489.

[5] CHEN, S. C., HUANG, C. Y., WANG, Y. T., HUANG, C. Y., YEN, H. W. (2020). Role of the crystallographic texture in anisotropic mechanical properties of a newly-developed hotrolled TRIP steel. In: Materials Science and Engineering: A, Vol. 790, pp. 139683-94. Elsevier Ltd. United Kingdom.

[6] AIŠMAN, D., STAŇKOVÁ, H., SKÁLOVÁ, L., MAŠEK, B. (2008). Testing of the parameters of the Q-P process in high strength lowalloyed steel. In: Danube Adria Association for Automation and Manufacturing, pp. 7-8. Vienna Austria: DAAAM International, Austria.

[7] DAI, J., MENG, Q., ZHENG, H. (2020). An innovative pathway to produce high-performance quenching and partitioning steel through ultra-fast full austenitization annealing. In: Materials Today Communications, Vol. 25, pp. 101272-79. Elsevier Ltd. United Kingdom.

[8] HAUSEROVÁ, D., DUCHEK, M., DLOUHÝ, J., NOVÝ Z. (2011). Properties of Advanced Experimental CMnSiMo Steel Achieved by QP Process, In: Procedia Engineering, Vol. 10, pp. 2961-2966. Elsevier Ltd. United Kingdom.

[9] HE, J., HAN, G., LI, S., ZOU, D. (2019). To correlate the phase transformation and mechanical behavior of QP steel sheets. In: International Journal of Mechanical Sciences, Vol. 152, pp. 198-210. Elsevier Ltd. United Kingdom. 
[10] KUČEROVÁ, L, BYSTRIANSKÝ, M., JENÍČEK, Š., FRANCISKO, P. (2017) Effect of deformation conditions on microstructure and mechanical properties of low alloyed steel. Manufacturing Technology, 2017, Vol. 17 No. 5, pp. 725-756. ISSN: 1213-2489.

[11] HUANG, H. Q, DI, H. S., YAN, N. et al. (2018). Hot Deformation Behavior and Processing Maps of a High Al-low Si TransformationInduced Plasticity Steel: Microstructural Evolution and Flow Stress Behavior. In: Acta Metallurgica Sinica (English Letters), Vol. 31, No. 5, pp. 503-514. Springer-Verlag, Germany.

[12] KUČEROVÁ, L., JIRKOVÁ, H., MAŠEK, B. (2015). Continuous Cooling of CMnSi TRIP steel. In: Materials Today: Proceedings, pp. 677S680. Elsevier Ltd., United Kingdom.

[13] KUČEROVÁ, L., BYSTRIANSKÝ, M. (2017). Comparison of thermo-mechanical treatment of C-Mn-Si-Nb and C-Mn-Si-Al-Nb TRIP steels. In: Procedia Engineering, pp.1856-1861. Elsevier Ltd., United Kingdom.
[14] El-SHERBINY, A., El-FAWKHRY, M. K., SHASH, A. Y., El-HOSSANY, T. (2020). Replacement of silicon by aluminum with the aid of vanadium for galvanized TRIP steel, In: Journal of Materials Research and Technology, Vol. 9, No. 3, pp. 3578-3589. Elsevier Ltd., United Kingdom.

[15] BARENYI, I., MAJERÍK, J., BEZECNY, J., KORBATA, M., SEDLÁK, J., JAROS, A. (2019). Material and Technological Aspects while Processing of Selected Ultra High Strength Steel, Manufacturing Technology, 2019, Vol. 19 No. 2, pp. 184-189. ISSN: 1213-2489.

[16] NOVOTNÝ, J., LYSONKOVÁ, I., MICHNA, Š., NÁPRSTKOVÁ, N. (2017). Research of Application Possibilities of Selected Mechanically Alloyed Metal Powders, $M a$ nufacturing Technology, 2017, Vol. 17 No. 5, pp. 811-815. ISSN: 1213-2489. 